NASA/TM—2007-214993

\title{
Effect of Temperature on Jet Velocity Spectra
}

\author{
James E. Bridges and Mark P. Wernet
}

Glenn Research Center, Cleveland, Ohio 


\section{NASA STI Program . . . in Profile}

Since its founding, NASA has been dedicated to the advancement of aeronautics and space science. The NASA Scientific and Technical Information (STI) program plays a key part in helping NASA maintain this important role.

The NASA STI Program operates under the auspices of the Agency Chief Information Officer. It collects, organizes, provides for archiving, and disseminates NASA's STI. The NASA STI program provides access to the NASA Aeronautics and Space Database and its public interface, the NASA Technical Reports Server, thus providing one of the largest collections of aeronautical and space science STI in the world. Results are published in both non-NASA channels and by NASA in the NASA STI Report Series, which includes the following report types:

- TECHNICAL PUBLICATION. Reports of completed research or a major significant phase of research that present the results of NASA programs and include extensive data or theoretical analysis. Includes compilations of significant scientific and technical data and information deemed to be of continuing reference value. NASA counterpart of peer-reviewed formal professional papers but has less stringent limitations on manuscript length and extent of graphic presentations.

- TECHNICAL MEMORANDUM. Scientific and technical findings that are preliminary or of specialized interest, e.g., quick release reports, working papers, and bibliographies that contain minimal annotation. Does not contain extensive analysis.

- CONTRACTOR REPORT. Scientific and technical findings by NASA-sponsored contractors and grantees.
- CONFERENCE PUBLICATION. Collected papers from scientific and technical conferences, symposia, seminars, or other meetings sponsored or cosponsored by NASA.

- SPECIAL PUBLICATION. Scientific, technical, or historical information from NASA programs, projects, and missions, often concerned with subjects having substantial public interest.

- TECHNICAL TRANSLATION. Englishlanguage translations of foreign scientific and technical material pertinent to NASA's mission.

Specialized services also include creating custom thesauri, building customized databases, organizing and publishing research results.

For more information about the NASA STI program, see the following:

- Access the NASA STI program home page at http://www.sti.nasa.gov

- E-mail your question via the Internet to help@sti.nasa.gov

- Fax your question to the NASA STI Help Desk at 301-621-0134

- Telephone the NASA STI Help Desk at 301-621-0390

- Write to: NASA Center for AeroSpace Information (CASI) 7115 Standard Drive Hanover, MD 21076-1320 
NASA/TM-2007-214993

AIAA-2007-3628

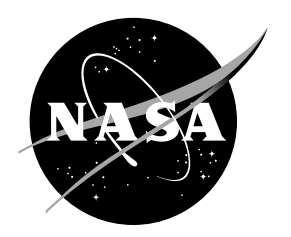

\section{Effect of Temperature on Jet Velocity Spectra}

James E. Bridges and Mark P. Wernet

Glenn Research Center, Cleveland, Ohio

Prepared for the

13th AIAA/CEAS/28th AIAA Aeroacoustics Conference

sponsored by the American Institute of Aeronautics and Astronautics

and the Confederation of European Aerospace Societies

Rome, Italy, May 21-23, 2007

National Aeronautics and

Space Administration

Glenn Research Center

Cleveland, Ohio 44135 
Trade names and trademarks are used in this report for identification only. Their usage does not constitute an official endorsement, either expressed or implied, by the National Aeronautics and Space Administration.

This work was sponsored by the Fundamental Aeronautics Program at the NASA Glenn Research Center.

Level of Review: This material has been technically reviewed by technical management.

Available from

NASA Center for Aerospace Information 7115 Standard Drive

Hanover, MD 21076-1320
National Technical Information Service 5285 Port Royal Road Springfield, VA 22161 


\title{
Effect of Temperature on Jet Velocity Spectra
}

\author{
James E. Bridges and Mark P. Wernet \\ National Aeronautics and Space Administration \\ Glenn Research Center \\ Cleveland, Ohio 44135
}

\begin{abstract}
Statistical jet noise prediction codes that accurately predict spectral directivity for both cold and hot jets are highly sought both in industry and academia. Their formulation, whether based upon manipulations of the Navier-Stokes equations or upon heuristic arguments, require substantial experimental observation of jet turbulence statistics. Unfortunately, the statistics of most interest involve the space-time correlation of flow quantities, especially velocity. Until the last 10 years, all turbulence statistics were made with single-point probes, such as hotwires or laser Doppler anemometry. Particle image velocimetry (PIV) brought many new insights with its ability to measure velocity fields over large regions of jets simultaneously; however, it could not measure velocity at rates higher than a few fields per second, making it unsuitable for obtaining temporal spectra and correlations. The development of timeresolved PIV, herein called TR-PIV, has removed this limitation, enabling measurement of velocity fields at high resolution in both space and time. In this paper, ground-breaking results from the application of TR-PIV to single-flow hot jets are used to explore the impact of heat on turbulent statistics of interest to jet noise models. First, a brief summary of validation studies is reported, undertaken to show that the new technique produces the same trusted results as hotwire at cold, low-speed jets. Second, velocity spectra from cold and hot jets are compared to see the effect of heat on the spectra. It is seen that heated jets possess 10 percent more turbulence intensity compared to the unheated jets with the same velocity. The spectral shapes, when normalized using Strouhal scaling, are insensitive to temperature if the stream-wise location is normalized relative to the potential core length. Similarly, second order velocity correlations, of interest in modeling of jet noise sources, are also insensitive to temperature as well.
\end{abstract}

\section{Introduction}

The need for turbulence statistics, such as turbulence intensity, velocity spectra, and spatial and temporal correlations, has been recognized in aeroacoustics for five decades. The quest for such statistics has led efforts to develop new measurement technologies, with advances in the field being paced by the tools available at any time in history. A paper by Laurence (ref. 1) in 1956, followed by many others, tackled this problem with the leading tool of the day, the hotwire anemometer. When laser Doppler anemometry (LDA) arrived, it was a breakthrough in allowing measurements in hot, high speed jets. However, given that its sampling was determined by the arrival times of seed particles, derivation of temporal statistics such as velocity spectra was fraught with problems, and it still suffered from the limitations of being a point measurement. Obtaining spatial correlations with either technique required extensive experimental time and complicated experimental setups.

When Particle Image Velocimetry (PIV) was developed, it allowed instantaneous measurement of velocity at many locations simultaneously, and quickly was put to use efficiently measuring mean and variance of velocity fields, and statistics such as spatial correlations (ref. 2). However, now the limitation was in the temporal domain, as the sampling in time was limited to a few tens of samples per second with PIV. Temporal spectra, statistics of most interest to jet noise theoreticians, were not possible. Again, with monumental effort, some limited resolution measurements of temporal correlations were obtained using two synchronized PIV systems (ref. 3), but the data was very difficult to obtain, and somewhat compromised by the sparse sampling in the time-delay domain. 
Recently, technology has been developed, particularly in the area of digital photography that allows very high bandwidth image acquisition. This, coupled with high energy pulsed lasers primarily used in metal cutting, has been creatively put together to allow high repetition PIV acquisition. The main tradeoffs involve limiting the field of view to minimize the image size (pixel count) and to maximize the beam energy of the light sheet. With pulse rates up to $50 \mathrm{kHz}$ and images of $50 \mathrm{k}$ pixels each, as described in this paper, over two seconds of data were acquired, providing an incredible amount of information for analysis.

\section{A. Motivation}

Turbulence spectra in heated jets are of intense interest to developers of jet noise prediction tools, given that most practical jets are heated. The effect of temperature on jet noise has been difficult to handle, primarily because of two conflicting observations. First, it is observed that jet noise primarily scales with jet exit velocity, a quantity that increases with temperature for a given nozzle pressure ratio. Noise measurements of jets at the same exit velocity but different static temperatures, such as was documented in (ref. 4) and reproduced in figure 1, show that once the jet has received some heat, its noise largely collapses for a given jet velocity. As seen in the figure, both the OASPL and the $90^{\circ}$ spectra for hot jets collapse at different static temperature ratios when the acoustic Mach number $\left(\mathrm{Ma}=V_{j} / c_{\infty}\right)$ is kept constant. Only at the far downstream angles are the sound fields affected by temperature. The spectra and the OASPL of the unheated jet, however, are significantly different from the hot jets at all angles. This observation would seem to indicate that the effect of temperature on the jet noise is very small aside from the initial change when the jet is first heated. However, as a second observation, all aeroacoustic theories relate the far-field sound pressure to the turbulent velocity and a density factor as a multiplier. Now if noise does not strongly change with temperature, the mean density of the turbulent jet fluid definitely does, decreasing inversely with the static temperature. One would expect from the theory that jet noise should decrease with increasing temperature if the turbulent velocity remained the same. Several possible explanations result from these observations: the addition of heat increases the turbulent kinetic energy (ref. 5); or possibly the velocity correlations change with heat to make it a much more efficient source of sound (refs. 6 and 7), or perhaps enthalpy-related sources, assumed small previously, play a more dominant role in hot jets (ref. 8). These hypotheses have been explored in the references given.
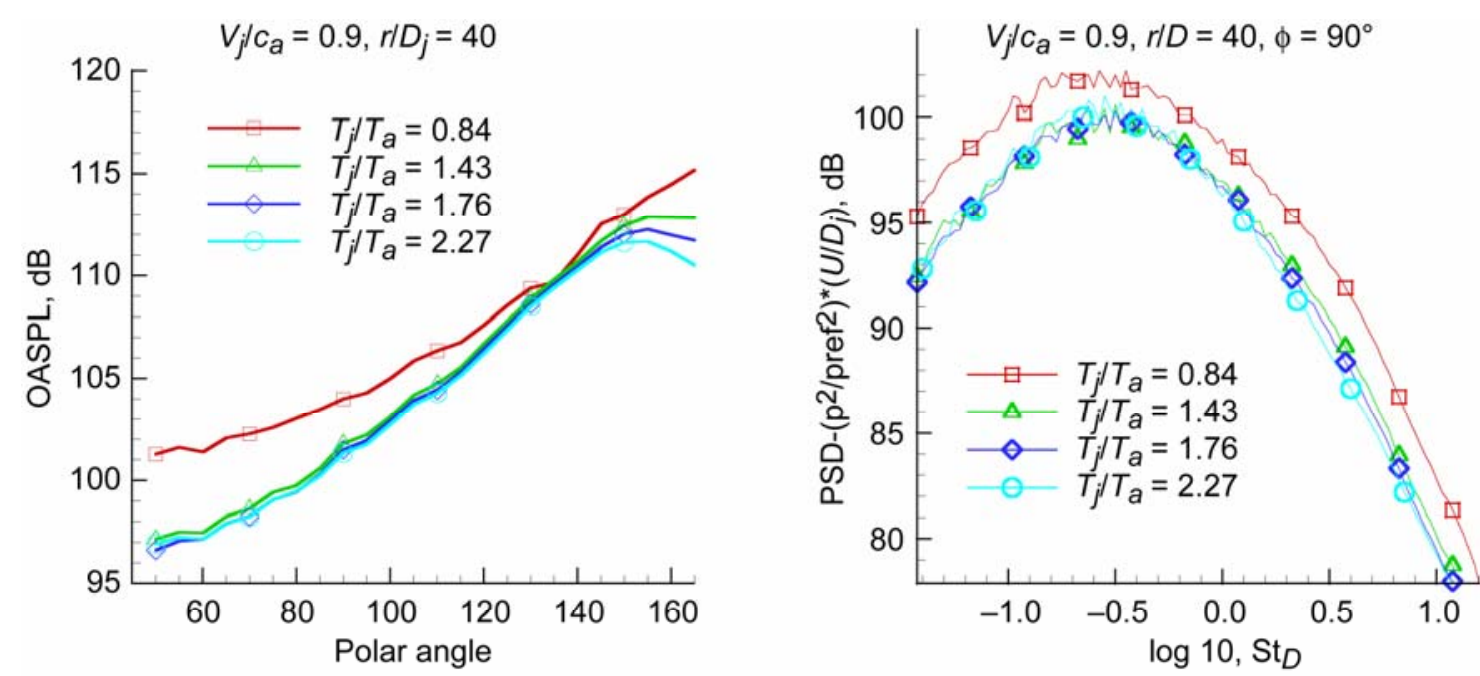

Figure 1.-Far-field jet noise from $M a=0.9$ jets, cold and static temperature ratios 1.43, 1.76, and 2.27; over all sound powerl evel (left), power spectral density for observer at $90^{\circ}$ to jet axis (right). $D_{j}=51 \mathrm{~mm}$; atmospheric attenuation removed and data projected to observer radius of 40 jet diameters. 
Recent measurements (ref. 9) using conventional PIV have shown that most velocity statistics do not vary significantly with temperature, especially when the change in shear layer growth is accounted for. When the mean centerline velocity at different temperatures is plotted versus an axial scale that is normalized by the potential core length, it collapses very nicely. Measurements also show that the turbulent kinetic energy also collapse with this axial rescaling, but that the cold jet has a lower overall level of turbulence intensity, by as much as 10 percent, as hot jets. In addition, heating does not appear to significantly alter the lengthscales or timescales of the jet. Finally, reductions in potential core length with temperature reduce the volume of turbulence that is contributing to the far-field noise.

If the turbulent kinetic energy and the lengthscales were relatively unaffected by temperature (after potential core length was accounted for), then one might expect that perhaps the efficiency of the turbulent velocity correlations responsible for noise generation has changed as a result of modifications in the temporal decay of these correlations. Or perhaps, in combination with changes in the speed of sound, the source compactness changed in such a way to offset the impact of reduced density on the source strength. If so, such changes should be reflected in the velocity spectra. To find out how temperature affects velocity spectra in jets, the newly developed TR-PIV was applied to a well-documented jet rig to obtain the necessary velocity spectra and other temporal statistics which impact how the turbulence of hot jets produce noise.

This paper presents the first application of Time-Resolved PIV (TR-PIV) technology to study the statistics of velocity fluctuations in hot and cold jets, and attempts to address the questions posed above.

In the following, the testing facility and the TR-PIV system are briefly described. An example showing comparisons with hot wire data, as well as illustrations of the spectral response of the measurements are provided. Comparisons of single-point statistics for several jets at jet acoustic Mach numbers of 0.90 and higher are made with previously established data. And finally, spectra from cold and hot jets are shown at various axial locations in the jet. All axial locations are normalized with respect to the jet potential core length through the Witze (ref. 10) parameter.

\section{Facilities, Instrumentation, and Test Matrix}

\section{A. Small Hot Jet Acoustic Rig (SHJAR)}

The Small Hot Jet Acoustic Rig (SHJAR), located within the AeroAcoustic Propulsion Laboratory (AAPL) at NASA's John H. Glenn Research Center, is a single-stream hot jet rig. The AAPL is a $65 \mathrm{ft}$ radius geodesic dome with its interior covered with sound absorbent wedges that provide the anechoic environment required to study propulsion noise from the several rigs that are located within. The jet rigs are positioned such that they exhaust out the open doorway, allowing seeding of the flow, and removing issues related to background noise from flow collectors. More detailed information on the facility and the jet rig are given in the reference by Bridges \& Brown (ref. 11). In typical testing, the SHJAR can cover the range of Mach numbers up to Mach 2, and static temperature ratios up to 2.8 using a hydrogen combustor and central air compressor facilities. For most testing SHJAR uses a $50 \mathrm{~mm}$ diameter nozzle, but can also operate larger nozzles with some limitation on cold setpoints at high Mach number. Total flow conditions for the rig are measured in the large plenum $0.6 \mathrm{~m}$ upstream of the nozzle. Figure 2 gives a clean presentation of the rig.

The nozzle used in this test was a simple convergent nozzle, designated as SMC000 and shown in figure 3. This nozzle has been used in many previously reported tests. It has an exit diameter $D_{j}=51 \mathrm{~mm}$ with a $5^{\circ}$ conic contraction and a $1 \mathrm{~mm}$ thick lip. 


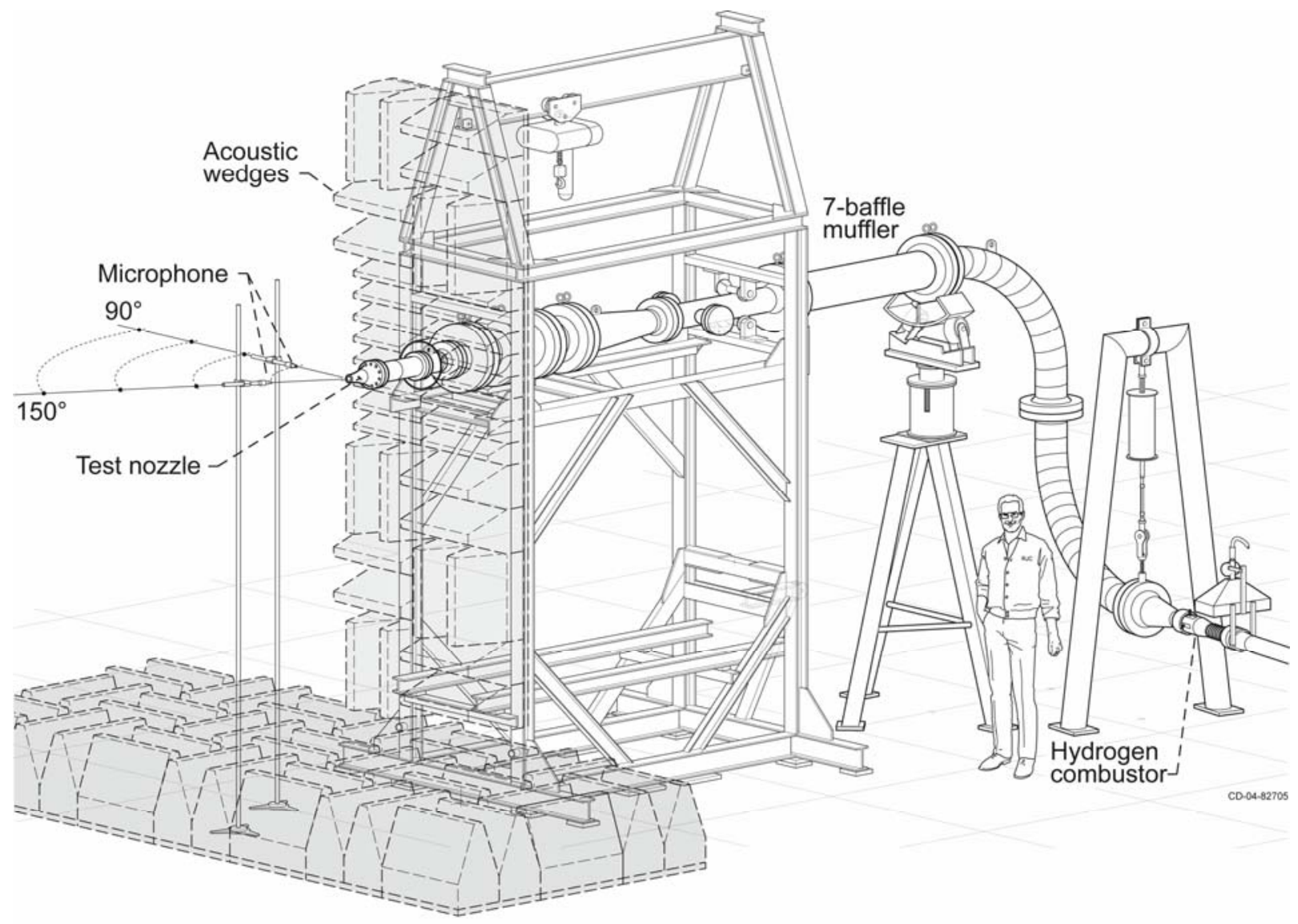

Figure 2.-Small Hot Jet Acoustic Rig in typical acoustic configuration.

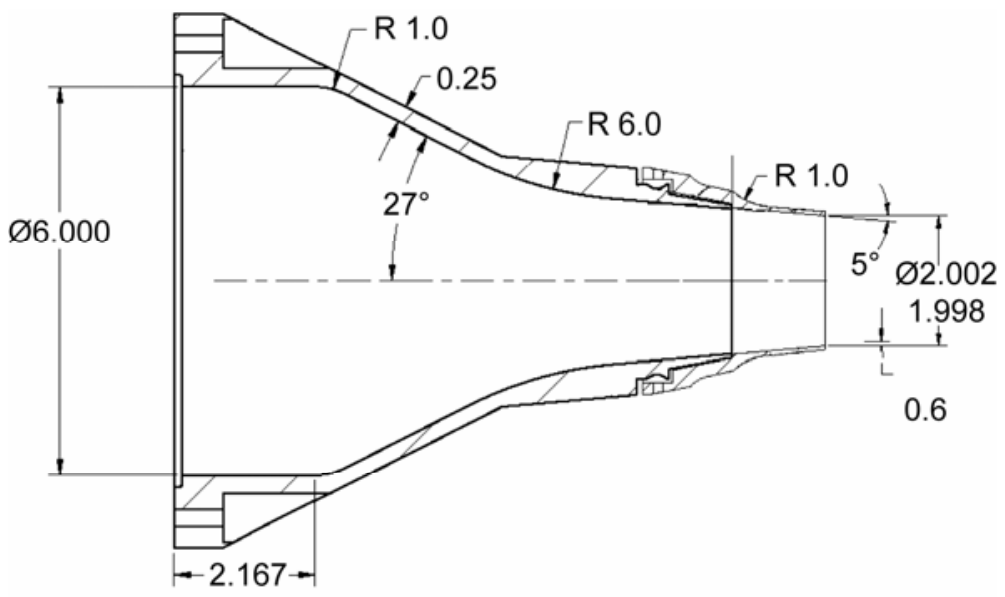

Figure 3.-Nozzle SMC000, a simple conic contraction nozzle of exit diameter $D_{j}=51 \mathrm{~mm}$ used in present study. 


\section{B. Temporal PIV}

In essence, Time-Resolved Particle Image Velocimetry (TR-PIV) is very similar to standard PIV with two exceptions. First, the camera was configured to store only the portion of the image required, minimizing the amount of information stored to only those regions of interest. The camera had on-board storage to record the images locally, saving the time-consuming (roughly 600:1 slower) part of downloading data to computer storage until after the acquisition was complete. The camera acquired images at a rate twice that of the final data recording rate, with each pair being used to construct one velocity vector field, until the cameras 1 GB storage capacity was filled. The camera was synchronized with a pair of high repetition pulsed lasers which, each firing at the final data recording rate, but at a time interval inversely proportional to the maximum velocity. Image processing was done using mostly the same correlation-based methods as in the standard PIV, but having sequential velocity fields allowed some additional checking of the vector field validity. In the final analysis, good seeding was the key to having fully populated vector fields essential for unbiased statistics.

The details of the TR-PIV implementation for this experiment were documented in an AIAA conference paper (ref. 12) and a journal paper (ref. 13), and are too extensive to present here. In the following, those aspects of the experimental setup that dictated the data sets used for flow statistics are given.

In this application of TR-PIV, two identical cameras were used to double to field of view available, each camera measuring displacements in the same vertical plane. Knowing that when temporal correlations were performed the correlations would remain significant over several diameters as coherent structures advected downstream, the field of view was optimized for a long narrow strip of flow approximately $0.5 D_{j}$ high by $6 D_{j}$ long. One set of data was acquired centered on the nozzle centerline and another set acquired centered on the nozzle lip line. The two sets nearly overlapped radially, but not quite. More importantly, each set was acquired at different offsets downstream, allowing data to be acquired from roughly $0.5<x / D_{j}<18$. Figure 4 illustrates the regions of the flow acquired, superposed on a plot of the axial turbulent velocity for a $\mathrm{Ma}=1.33$ hot jet. The purple box in the figure represents the field of view from any one acquisition sequence.

Figure 5 is a photo of the final configuration for measuring along the nozzle lip line, with the beamforming optics being contained within a sheet metal box, emerging directly downstream of the nozzle lip, The dual cameras can be seen in the picture, viewing the beam from right angles and recording the first 6 jet diameters together. The beam-forming optics were kept clean by pressurizing the sheet metal box so that air came out the beam opening at a velocity higher than the jet at that downstream location. Before this air was added the optics became too dirty to use within a few seconds of seeding the flow. After the addition of the purge air the optics stayed clean for several acquisitions, or a few minutes.

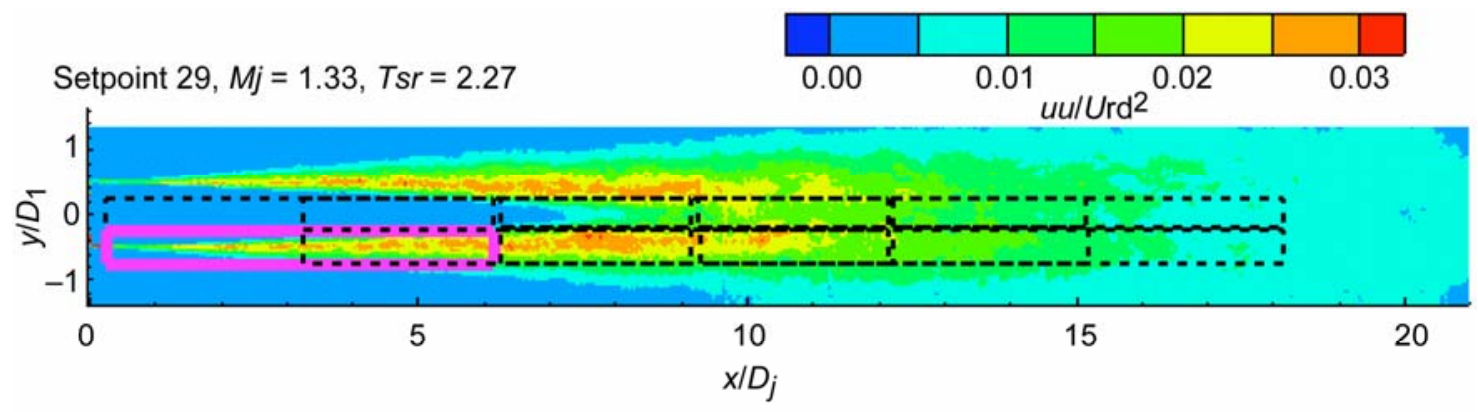

Figure 4.-Locations of TR-PIV acquisitions. Boxes indicate fields of view, with purple box indicating the size of field of view for any single acquisition sequence. 


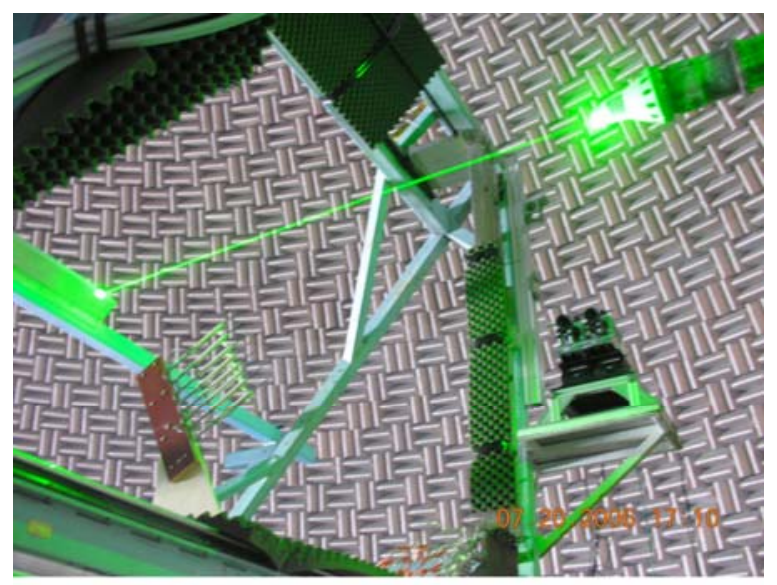

Figure 5.-Picture of TR-PIV setup in SHJAR. Beam introduced from covered optics directly downstream of nozzle, directed at nozzle lip, upper right. Dual cameras, lower right, record particle images at right angles to beam.

\section{Test Conditions}

Flow conditions are set based on jet exit velocity relative to ambient speed of sound $\left(V_{j} / c_{\infty}=\mathrm{Ma}\right.$ or acoustic Mach number) and static temperature ratio $\left(T_{s} / T_{\infty}\right)$ relative to ambient temperature, in a manner consistent with Tanna et al. (ref. 14). In fact, the test points acquired in this study coincide with those specified by Tanna. Two cold setpoints were acquired, one at $\mathrm{Ma}=0.5$ (not listed in the table), used only for comparison with hotwire data, and one at $\mathrm{Ma}=0.9$. Two other setpoints were acquired at $\mathrm{Ma}=0.9$, $T_{s} / T_{\infty}=1.76$ and 2.23. Higher Ma (but still subsonic gas Mach number) setpoints were run at $\mathrm{Ma}=1.33$, $T_{s} / T_{\infty}=1.76$ and 2.23, to look at effects of high speed. Definitions of setpoints used in the test are given in table 1. Included in the table are the potential core lengths as calculated from Witze (ref. 10) scaling.

TABLE 1.-SETPOINT DEFINITIONS FOR TEST MATRIX

\begin{tabular}{|c|c|c|c|}
\hline Setpoint & Ma $\left(=V_{j} / C_{\infty}\right)$ & $T_{s} / T_{\infty}$ & $x_{C} / D_{j}$ \\
\hline 7 & 0.90 & 0.84 & 7.8 \\
\hline 23 & 0.50 & 1.76 & 5.7 \\
\hline 27 & 0.90 & 1.76 & 6.0 \\
\hline 29 & 1.33 & 1.76 & 6.4 \\
\hline 36 & 0.90 & 2.27 & 5.5 \\
\hline 38 & 1.33 & 2.27 & 5.8 \\
\hline
\end{tabular}

\section{Definition of Statistics Presented}

For clarity, the following statistics are defined for velocity components $u_{i}(\vec{x}, t)$ over a region containing the points $\vec{X}$ and time interval $T$.

Mean velocity at flow location $\vec{x}$ is

$$
U_{i}(\vec{x})=\frac{1}{T} \int_{t=0}^{t=T} u_{i}(\vec{x}, t) d t
$$

and the fluctuating velocity component is denoted as $v_{i}$

$$
v_{i}(\vec{x}, t)=u_{i}(\vec{x}, t)-U_{i}(\vec{x})
$$


The turbulent velocity correlation between two velocity components separated in space $\vec{\xi}$ and time $\tau$, and with the correlation centered at $\vec{x}$ is

$$
R_{v_{i} v_{k}^{\prime}}=\overline{v_{i} v_{k}^{\prime}}(\vec{\xi}, \tau ; \vec{x})=\frac{1}{T} \int_{t=0}^{t=T} v_{i}(\vec{x}+\vec{\xi} / 2, t) v_{k}(\vec{x}-\vec{\xi} / 2, t-\tau) d t
$$

Prime denotes separation in time and/or space. The special case of correlation at $\vec{\xi}=\tau=0, i=k$, the commonly known mean-square or variance of velocity becomes $\overline{v_{i} v_{i}}(0,0 ; \vec{x})$. The conventional power spectral density (PSD) of velocity can be defined as the Fourier Transform of the velocity correlation with $\vec{\xi}=0$ :

$$
G_{v_{k} v_{k}}(f ; \vec{x})=\frac{1}{T} \int_{t=0}^{t=T} \overline{v_{k} v_{k}}(0, \tau ; \vec{x}) e^{-i \omega \tau} d \tau, \omega=2 \pi f
$$

In this paper, only statistics using the axial component of velocity $\overline{v_{1} v_{1}}$ are described, although both radial and axial components were acquired. In the presentation of data, the statistics of velocity are normalized by the exit jet velocity $U_{j}$. Note that since power spectral density is plotted as a function of Strouhal number $\left(\mathrm{St}_{\mathrm{D}}=f D_{j} / U_{j}\right)$, the units are $\mathrm{uu} / U_{j}^{2} / \mathrm{St}_{\mathrm{D}}$ such that when the PSD is integrated over Strouhal number the mean-square value is recovered.

\section{Results}

\section{A. Validation}

To determine the extent to which the TR-PIV results could be trusted, data was initially acquired at $\mathrm{Ma}=0.5$ unheated, and compared with hotwire data acquired in the facility in a previous test. Later it was also decided to maximize the sampling rate and to use the results to determine if the observed flattening of the velocity spectra was an apparent noise floor correlating to the sample rate. Comparisons were made between the hotwire and TR-PIV spectra at several locations on the shear layer. Figure 6 shows a sample comparison at $x / D_{j}=3, y / D_{j}=-0.5$ (nozzle lip line). When comparing the $10 \mathrm{kHz}$ hotwire data against the $10 \mathrm{kHz}$ TR-PIV data the most obvious difference was at the high frequencies, where the TR-PIV spectra does not follow the hotwire spectra at the highest frequencies. This was understood to be an artifact of aliasing, since the hotwire signal had appropriate anti-aliasing filtering applied before sampling, whereas the TR-PIV method does not allow for such a correction. The fact that aliasing was affecting the highest frequencies was additionally confirmed by acquiring TR-PIV data at a $25 \mathrm{kHz}$ rate for select cases. The higher sample rate data follows the hotwire data very closely as seen in the figure. Not shown here were exercises in which the $25 \mathrm{kHz}$ data were further sub-sampled with and without anti-aliasing filtering, reproducing the high frequency error observed in the $10 \mathrm{kHz}$ data. More details on this validation are contained in reference 13. For the present study, only the $10 \mathrm{kHz}$ data was used. Although the spectra are somewhat compromised at high frequency, as seen in figure 6 , still the relative effects of temperature and Mach number are captured. 


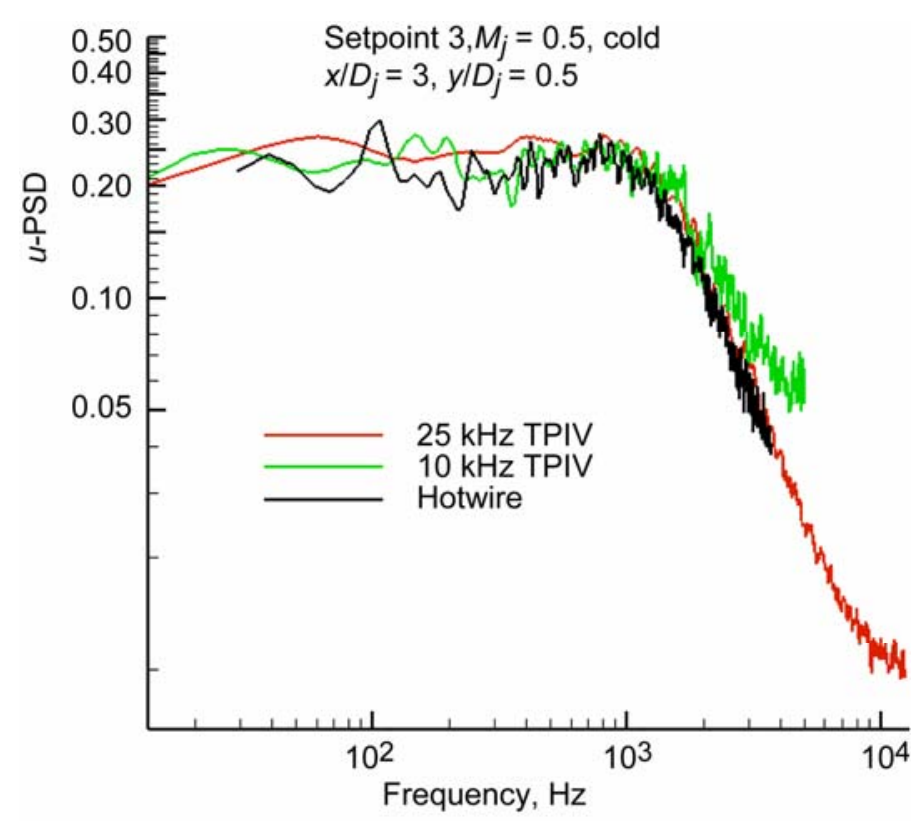

Figure 6.-Power Spectral Density of axial velocity, $x / D_{j}=3$, $y / D_{j}=0.5, \mathrm{Ma}=0.5$, cold. Plot shows spectra from 10 and $25 \mathrm{kHz}$ sample rate TR-PIV.

As a second check, the mean-square velocities $\overline{v_{1} v_{1}} / U j^{2}$ measured by the TR-PIV system were compared against standard PIV data from previous tests. The measurements are separated by several years, and use completely different optical instrumentation and processing methods. Figure 7 compares the axial turbulence of an unheated $\mathrm{Ma}=0.9$ jet (setpoint 7) against that of $\mathrm{Ma}=0.9$ jet with static temperature ratio 1.76 (setpoint 27). From inspection, the two measurements are within 5 percent of each other, and closer inspection reveals subtle differences that reflect the level of error in each measurement. The biggest source of error appears near the edge of the PIV fields of view-this leads to the vertical 'banding' of the data where data from the different fields of view are merged.

\section{B. Cold Versus Hot Jet Mean and Mean-Square Velocity}

In reference 9, it was shown that mean and standard deviation of the velocity field in both cold and hot jets collapsed fairly well when the streamwise distance was normalized by the potential core length. The effect of temperature and jet speed on the potential core length was found to be well-predicted by the correlation of Witze (ref. 10) for subsonic jets $x_{w}=x \kappa\left(\rho_{\infty} / \rho_{j}\right)^{0.50}, \kappa=0.08\left(1-0.16 M_{j}\right)\left(\rho_{\infty} / \rho_{j}\right)^{-0.22}$ where $M_{j}$ is an ideally expanded Mach number for the jet, and is written in terms of the acoustic Mach number as $\operatorname{Ma}\left(\rho_{j} / \rho_{\infty}\right)^{0.50}, \rho_{j}$ and $\rho_{\infty}$ denote the exit and ambient mean density respectively. When $x$ is replaced with the potential core length $x_{c}, x_{w}$ collapses for all jets, removing the effect of velocity and temperature from the core length such that $x_{w} / D_{j}$ equals 0.50 , or in terms of exit radius $x_{w} / r_{j}$ equals 1.0. In effect, the potential core length may be calculated as $x_{c} / D_{j}=\left(\rho_{\infty} / \rho_{j}\right)^{-0.50} /(2 \kappa)$.

This normalization not only collapses the end of the potential core fairly well, it does a fair job of collapsing the mean velocity decay region as well. 

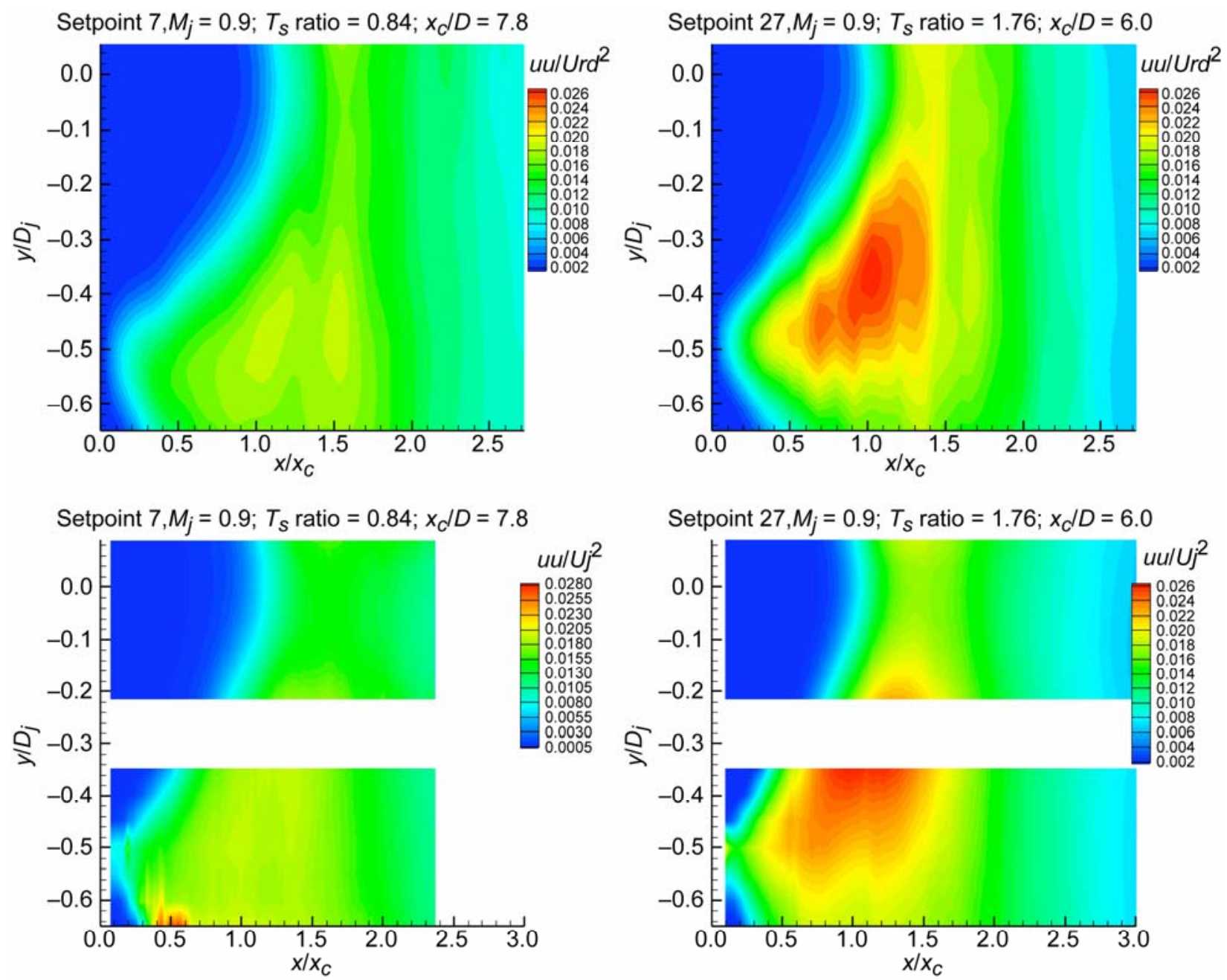

Figure 7.-Comparison of mean-square velocity as measured by standard PIV (top row) and by TR-PIV (bottom row) for unheated (left) and heated $\left(T_{S} / T_{\infty}=1.76\right.$, right) jets.

Figures 8 and 9 show the mean axial velocity field and its variance for all set points defined in table 1, as acquired using the TR-PIV system. These plots are a mosaic of data from all the fields of view acquired in each flow. In the plots of mean axial velocity, the similarity of the plots show the collapse of the jet mean flow field when the axial coordinate was rescaled by the potential core length. The plots of mean-square velocity also have quite a bit of similarity, with some notable exceptions. First, the unheated $\mathrm{Ma}=0.9$ (setpoint 7) case has obviously been strongly compromised on its low-speed side, with meansquare values which differ from physically reasonable values in a small region near $x / x_{c}=0.5, y / D_{j}>0.6$. Results from this region will not be used in subsequent analysis. The second feature noted was how the peak turbulence levels all occurred inside the lip line near $x / x_{c}=1$. Furthermore, the peak values of meansquare velocity at all jet conditions were nearly the same at 0.025 , except the unheated, $\mathrm{Ma}=0.9$ case. Here the peak in mean-square velocity was 0.02 . There was also an indication that for a given temperature ratio, increasing the Mach number reduced the turbulence slightly, although the difference was more in the extent of the region of high mean-square values rather than in the peak value. Note that none of these flows are supersonic relative to the speed of sound in the jet fluid, so compressibility effects are minimal. 


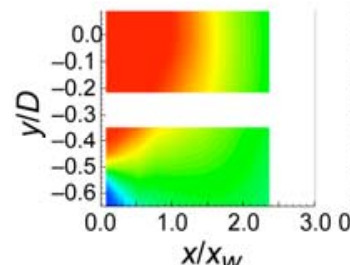

$$
\mathrm{Ma}=0.9
$$

$T_{s} / T_{a}=0.84$

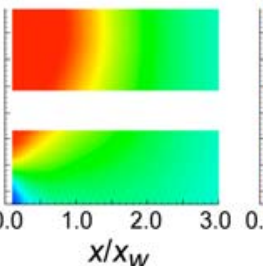

$\mathrm{Ma}=0.5$

$T_{s} / T_{a}=1.76$

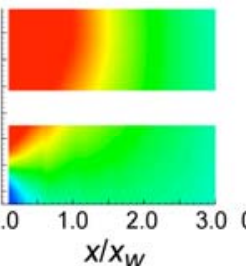

$\mathrm{Ma}=0.9$

$T_{s} / T_{a}=1.76$

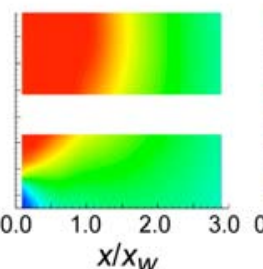

$\mathrm{Ma}=1.33$

$T_{s} / T_{a}=1.76$

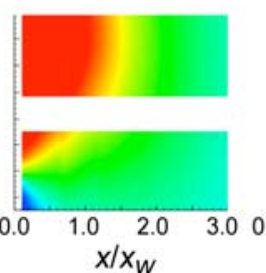

$\mathrm{Ma}=0.9$

$T_{s} / T_{a}=2.27$

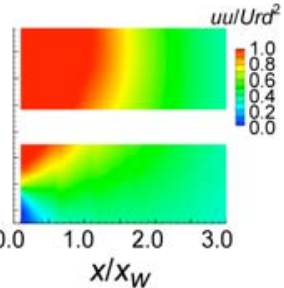

$\mathrm{Ma}=1.33$

$T_{s} / T_{a}=2.27$

Figure 8.-Mean axial velocity of all jet flows computed from TR-PIV. Axial coordinate normalized by potential core length, $x_{C}$.

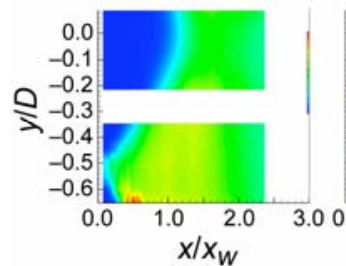

$\mathrm{Ma}=0.9$

$T_{s} / T_{a}=0.84$

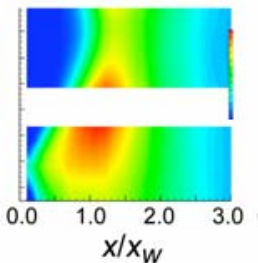

$\mathrm{Ma}=0.5$

$T_{s} / T_{a}=1.76$

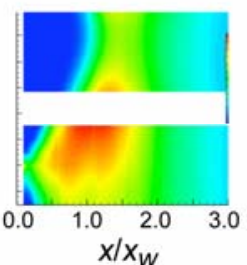

$\mathrm{Ma}=0.9$

$T_{s} / T_{a}=1.76$

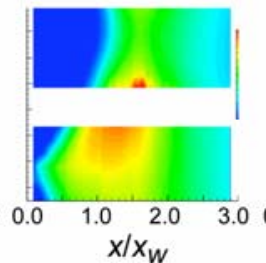

$\mathrm{Ma}=1.33$

$T_{s} / T_{a}=1.76$

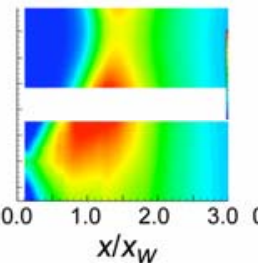

$\mathrm{Ma}=0.9$

$T_{s} / T_{a}=2.27$

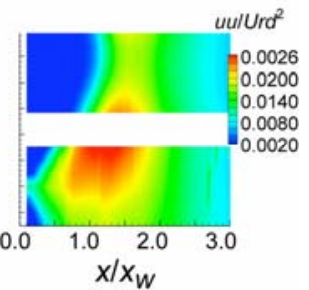

$\mathrm{Ma}=1.33$

$T_{s} / T_{a}=2.27$

Figure 9.-Variance of axial velocity from TR-PIV. Axial coordinate normalized by potential core length, $x_{C}$.

\section{Cold Versus Hot Jet Velocity Spectra}

First, velocity spectra will be compared at several locations (both on the centerline and the lip-line) for an unheated as well as a heated jet. Next, velocity spectra for jets of three different temperatures but the same exit velocity will be compared at similar locations in the jet. Finally, velocity spectra for all the measured cases at different temperatures and different velocities will be compared using surface plots.

To compare spectra at similar locations in jets of different speeds and temperatures in a meaningful way, the locations for comparison were chosen as constant values of $x / x_{c}$. Of particular interest to theoreticians was the behavior of the spectra near the end of the potential core, which is found to be the most dominant source region for jet noise. Figure 10 shows a representative normalized mean square velocity plot with circles at locations where velocity spectra were extracted from the datasets.

Figure 11 show the velocity spectra from a given jet flow at different locations on a single plot for the unheated jet. It is interesting that at locations on the jet centerline within the potential core there was significant unsteadiness at $\mathrm{St}_{\mathrm{D}}=0.4$. Moving downstream along the centerline, the velocity spectra increased at lower frequencies quite dramatically, accounting for most of the increase in turbulent kinetic energy as the potential core closed out. Beyond the potential core, the spectra reached a simple shape being nearly flat across low frequencies until kneeing over to a simple linear (in these log-log coordinates) roll-off. The frequency at which the knee occurred decreased with downstream distance.

On the lip line $\left(y / D_{j}=-0.5\right)$, the spectra started out flat over the frequencies measured $\left(\mathrm{St}_{\mathrm{D}}<1\right)$, and rose with increasing distance downstream. By $x / x_{c}=0.5$ a knee developed within the measured frequency range, roughly at $\mathrm{St}_{\mathrm{D}}=0.5$, and this knee progressed to lower frequencies with downstream distance. 


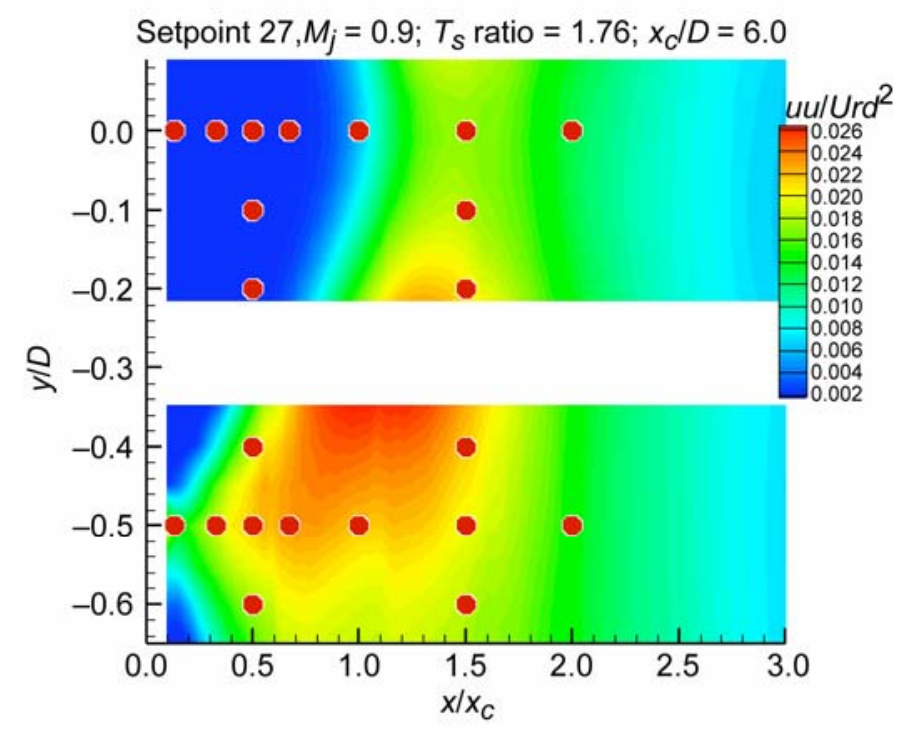

Figure 10.-Map of turbulence field showing locations of velocity spectra in following figures.
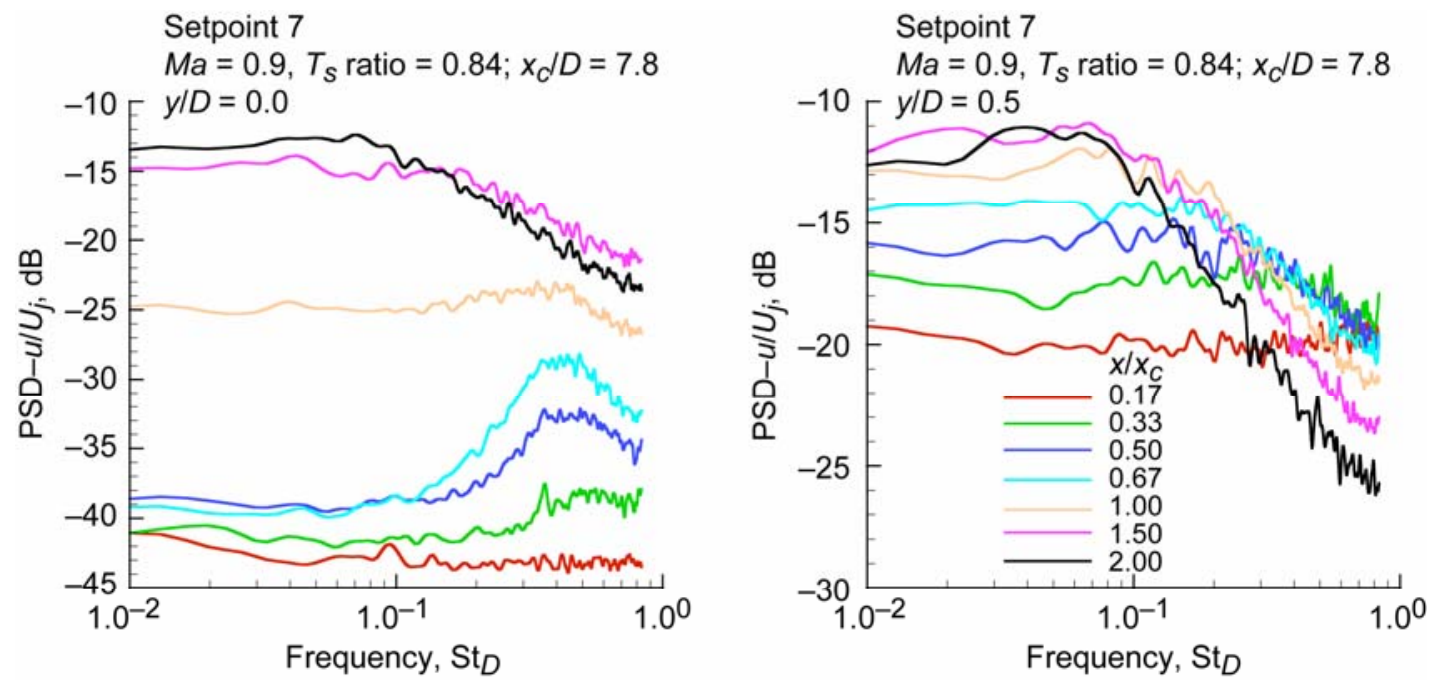

Figure 11.-Velocity spectra for locations on centerline (left) and lipline (right) for axial locations shown in figure 10. Setpoint $7\left(M a=0.9, T_{S} / T_{\infty}=0.84\right)$.

How did the addition of heat change this picture? Velocity spectra are plotted in figure 12 for a jet with the same velocity $(\mathrm{Ma}=0.9)$ but with a static temperature ratio of 2.27 (setpoint 36 ). Recall that spectra in both cold and hot jets were gathered at locations that are similarly positioned relative to potential core length. The spectral behavior of the hot jet velocity field were very similar to that of the unheated jet, but with slightly higher values as expected from the higher values of turbulence.

Variations in the power spectral density of axial velocity across the jet shear layer are shown for two different axial locations in figures 13 and 14. 

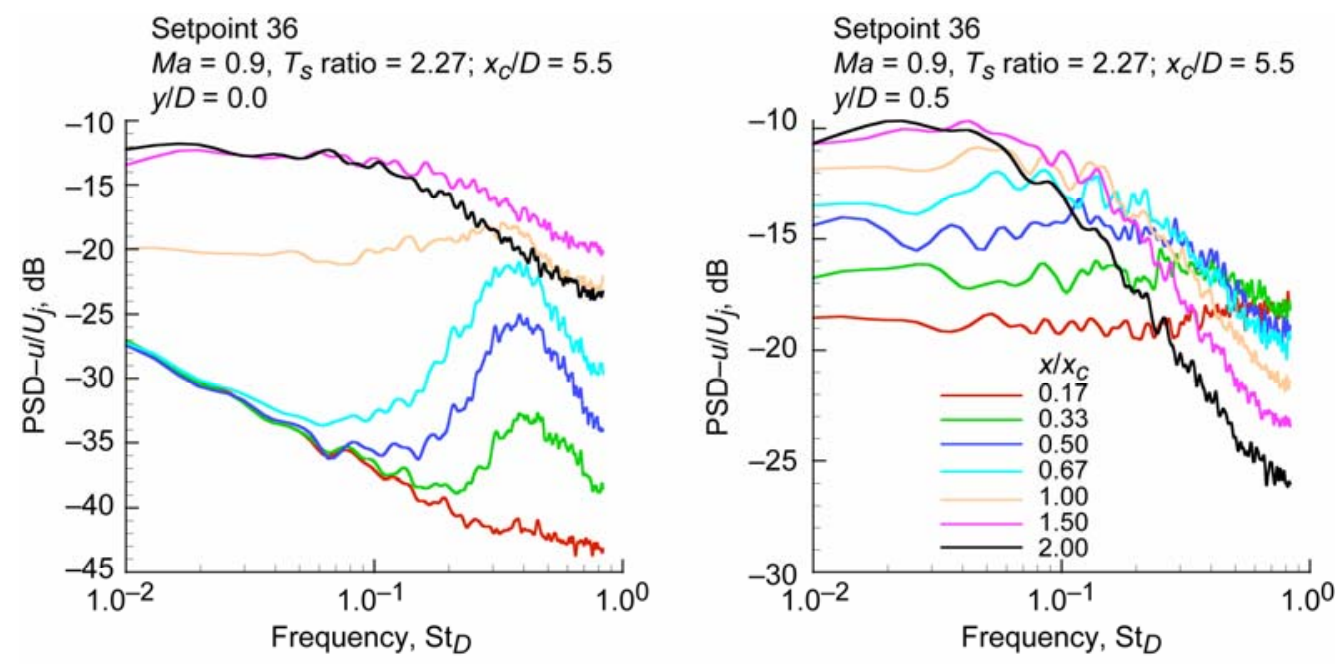

Figure 12.-Velocity spectra for locations on centerline (left) and lipline (right) for axial locations shown in figure 10. Setpoint $36\left(M a=0.9, T_{S} / T_{\infty}=2.27\right)$.
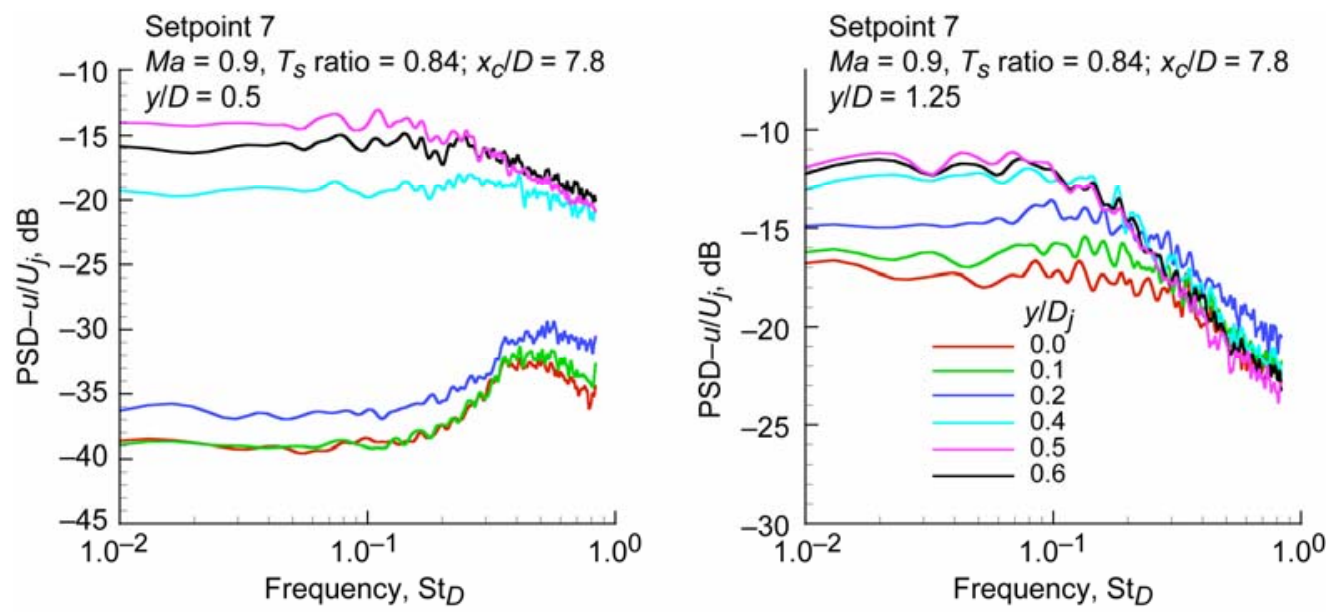

Figure 13.-Velocity spectra for locations $x / x_{C}=0.5$ (left) and $x / x_{C}=1.25$ (right) at radial locations given in figure 10; setpoint $7\left(M a=0.9, T_{S} / T_{\infty}=0.84\right)$.
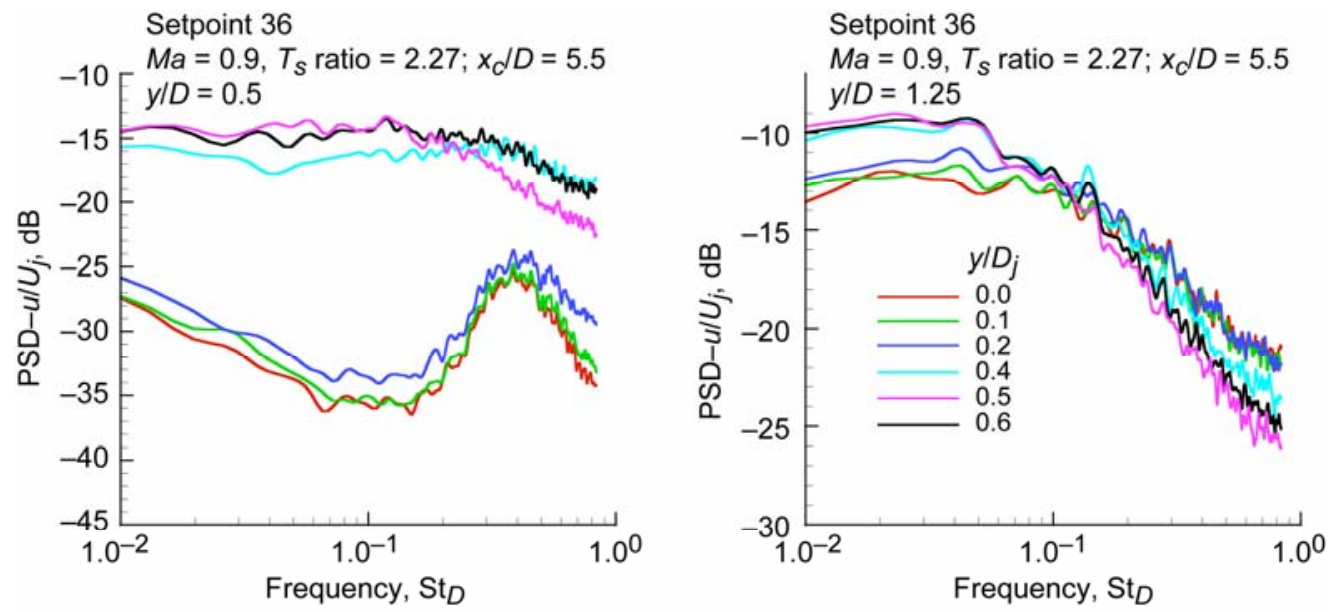

Figure 14.-Velocity spectra for locations $x / x_{C}=0.5$ (left) and $x / x_{C}=1.25$ (right) at radial locations given in figure 10; setpoint $36\left(M a=0.9, T_{S} / T_{\infty}=2.27\right)$. 
To directly assess the effect of temperature on the jet velocity spectra, figure 15 was prepared. Each of the eight panels in the figure compares velocity spectra at the same $x / x_{c}$ in jets with static temperature ratios of $0.84,1.76$, and 2.27. In all locations, there was a discrepancy between the unheated jet and the two hot jets. This discrepancy was not in the spectral shape, but rather in the amplitude, corresponding to the differences in overall turbulent kinetic energy. The two heated jets were very similar at all locations.

To cover the impact of jet velocity on the velocity spectra of hot jets, figure 16 (jet centerline) and figure 17 (jet lip line) were prepared. In these figures, power spectral density of axial velocity are plotted as a function of Strouhal number $\mathrm{St}_{\mathrm{D}}$ and normalized axial coordinate $x / x_{c}$ for each of the jet conditions listed in table 1. By comparing across all the jet conditions tested, covering $0.5<\mathrm{Ma}<1.33$, we see the relative insensitivity of the velocity spectra to jet velocity over this range of speeds. Again, note that none of these flows had aerodynamic Mach numbers greater than unity and hence compressibility effects are expected to be minimal.

\section{Cold Versus Hot Jet Velocity Correlations}

One other statistic of importance in aeroacoustics that this new data enables to compute is the secondorder space-time correlation of axial velocity. From this statistic one can deduce length and timescales, and it is also of interest to observe the effect of temperature on this statistic. By way of orienting to the data presentation, figure 18 shows two prototypical results in detail. Correlations $\overline{v_{1} v_{1}^{\prime}}(\vec{\xi}, \tau ; \vec{x})$ at two locations on the centerline of the cold $\mathrm{Ma}=0.9$ jet were extracted, one acquired within the potential core of the jet $\left(x / x_{c}=0.5\right)$ and the second one downstream of the core at $\left(x / x_{c}=1.5\right)$. The nondimensionalized space coordinate (shown on the vertical axis) is the axial separation, and the normalized time-delay is shown on the horizontal axis. First, note that although the spatial coordinates and correlation contour levels have the same ranges on each plot, the two plots have different ranges for the time coordinate as the longer correlation and slower convection velocity downstream required more range. At first glance, the main feature of the correlations was a diagonal ridge which marked the average convection of the turbulence. However, within the potential core the correlations had a substantial and very strong negatively correlated region on either side of the main peak, whereas downstream of the potential core, there was only a very little negatively correlated region and the correlation was only slightly below zero. This was a distinctive difference between correlations taken upstream and downstream of the potential core. The practical significance of this may not be important considering the relatively small level of turbulence within the potential core. It should also be noted that the lack of smoothness in contour levels along their main diagonal was an artifact of the 'sampling' or grid at which the correlations were made, and not a physically significant detail. Finally, the two plots have different ranges of data in the spatial coordinate because of the differences in relative location of the reference point to the edge of the field of view of the dataset. This was true for different jet flow conditions even at the same reference location because the normalizing parameter, i.e. the potential core length, was different. Reference locations were chosen that maximized the range of the correlations for all conditions given the fixed physical fields of view over which the data was acquired.

One other feature of possible importance in source modeling is the spatial size of the correlation. Although the correlation values away from the peak diagonal line were very small, they exhibited structures which show there is considerable size (1.5 to $\left.2.0 D_{j}\right)$ to a so called 'correlated patch of fluid'. This finding may be significant in modeling of the aeroacoustic sound sources, especially at high frequencies where the correlation is now of the same order or even exceeds the wavelength of the sound. That these lines of isocorrelation have the same slope as the main convection ridge indicates that these are details of the turbulence, not sound waves themselves.

Having oriented the reader to the presentation of the space-time correlation, the space-time correlations of axial velocity for the reference locations given in figure 10 are presented in figure 19 (centerline) and figure 20 (lip line) for all the jet flow conditions listed in table 1. Again, note that the time-delay coordinate has different ranges depending on $x / x_{c}<1$ or $x / x_{c} \geq 1$. 

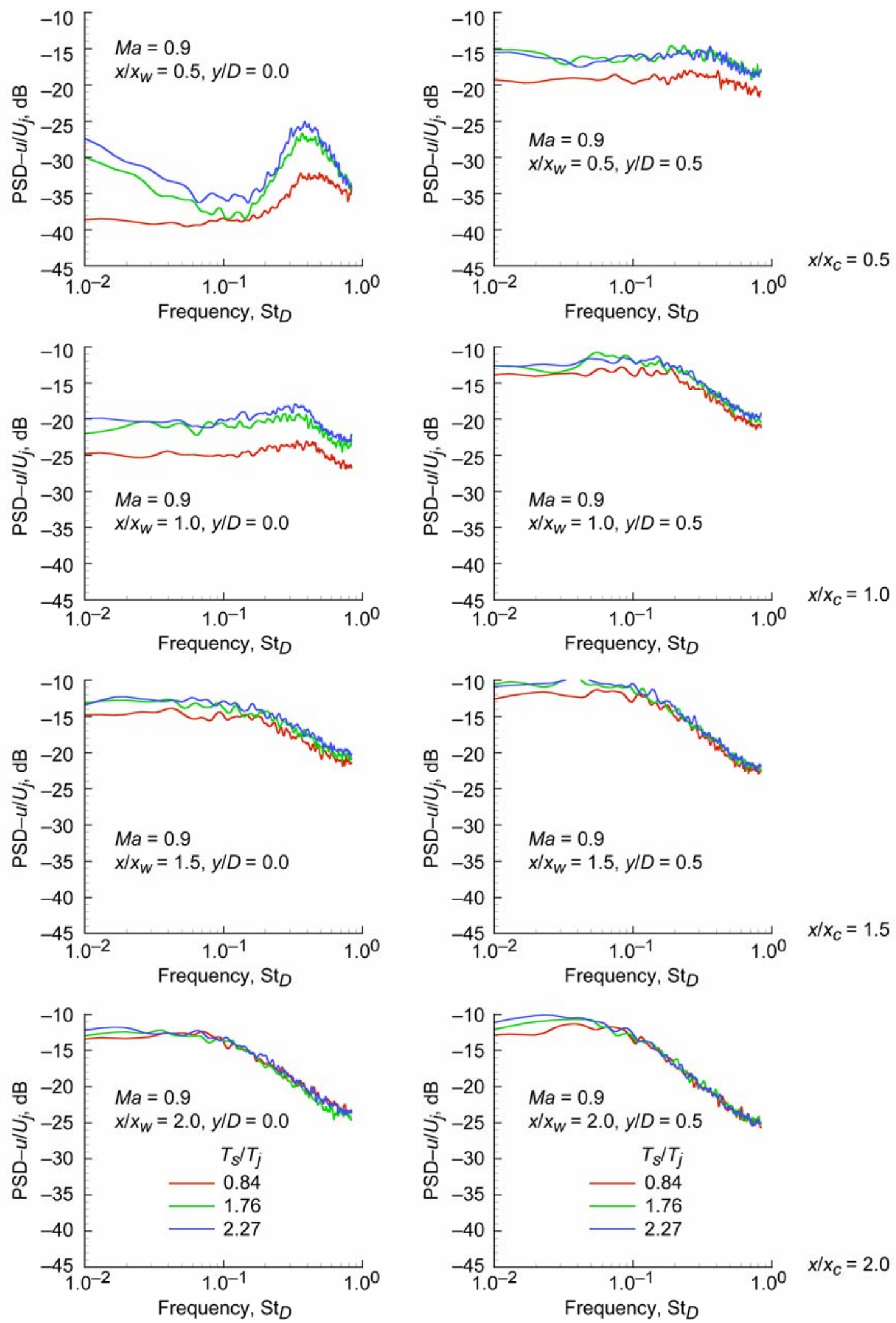

Figure 15.-Comparison of velocity spectra for $\mathrm{Ma}=0.9$ jets with three different static temperature ratios: $T_{S} / T_{\infty}=0.84,1.76$, and 2.27 . Each row has spectra for locations relative to potential core length: $x / x_{C}=0.5,1.0,1.5$, and 2.0. Left column: $y / D_{j}=0$, right column: $y / D_{j}=-0.5$. 


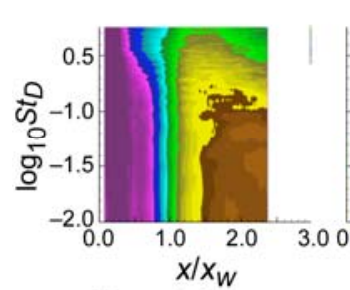

$\mathrm{Ma}=0.9$

$T_{S} / T_{a}=0.84$

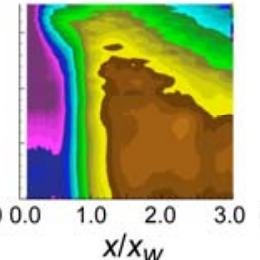

$\mathrm{Ma}=0.5$

$T_{S} / T_{a}=1.76$

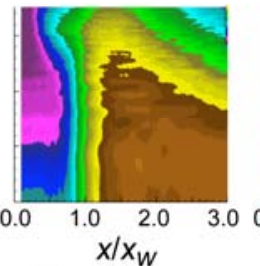

$\mathrm{Ma}=0.9$

$T_{s} / T_{a}=1.76$

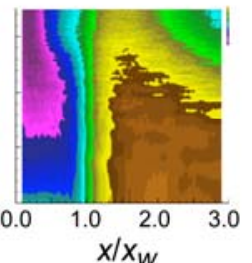

$\mathrm{Ma}=1.33$

$T_{s} / T_{a}=1.76$

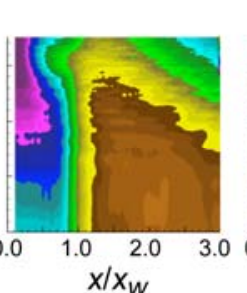

$\mathrm{Ma}=0.9$

$T_{s} / T_{a}=2.27$

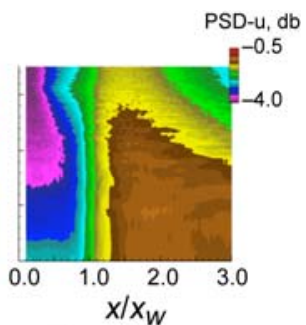

$\mathrm{Ma}=1.33$

$T_{S} / T_{a}=2.27$

Figure 16.-Power spectral density on jet centerline as a function of axial location for jet flow condition indicated at bottom of figure.

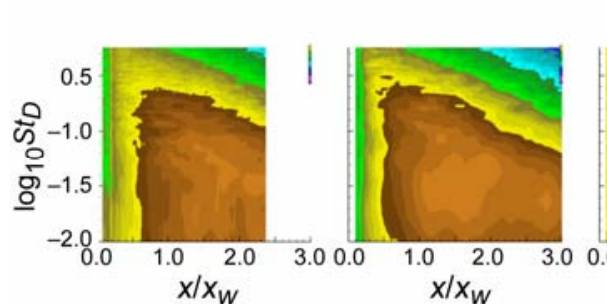

$\mathrm{Ma}=0.9$

$T_{s} / T_{a}=0.84$
$\mathrm{Ma}=0.5$

$T_{S} / T_{a}=1.76$

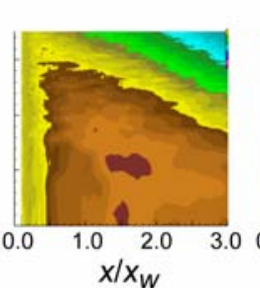

$\mathrm{Ma}=0.9$

$T_{S} / T_{a}=1.76$

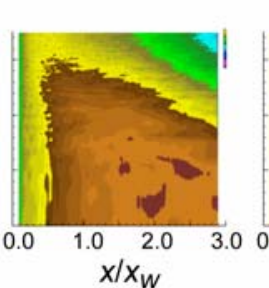

$\mathrm{Ma}=1.33$

$T_{s} / T_{a}=1.76$

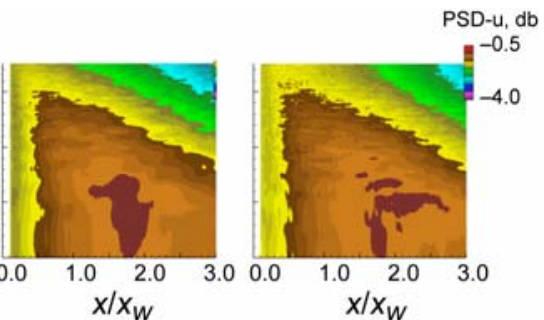

$\mathrm{Ma}=0.9$

$T_{s} / T_{a}=2.27$
$\mathrm{Ma}=1.33$

$T_{s} / T_{a}=2.27$

Figure 17.-Power spectral density on jet lip line as a function of axial location for jet flow conditions indicated at bottom of figure.
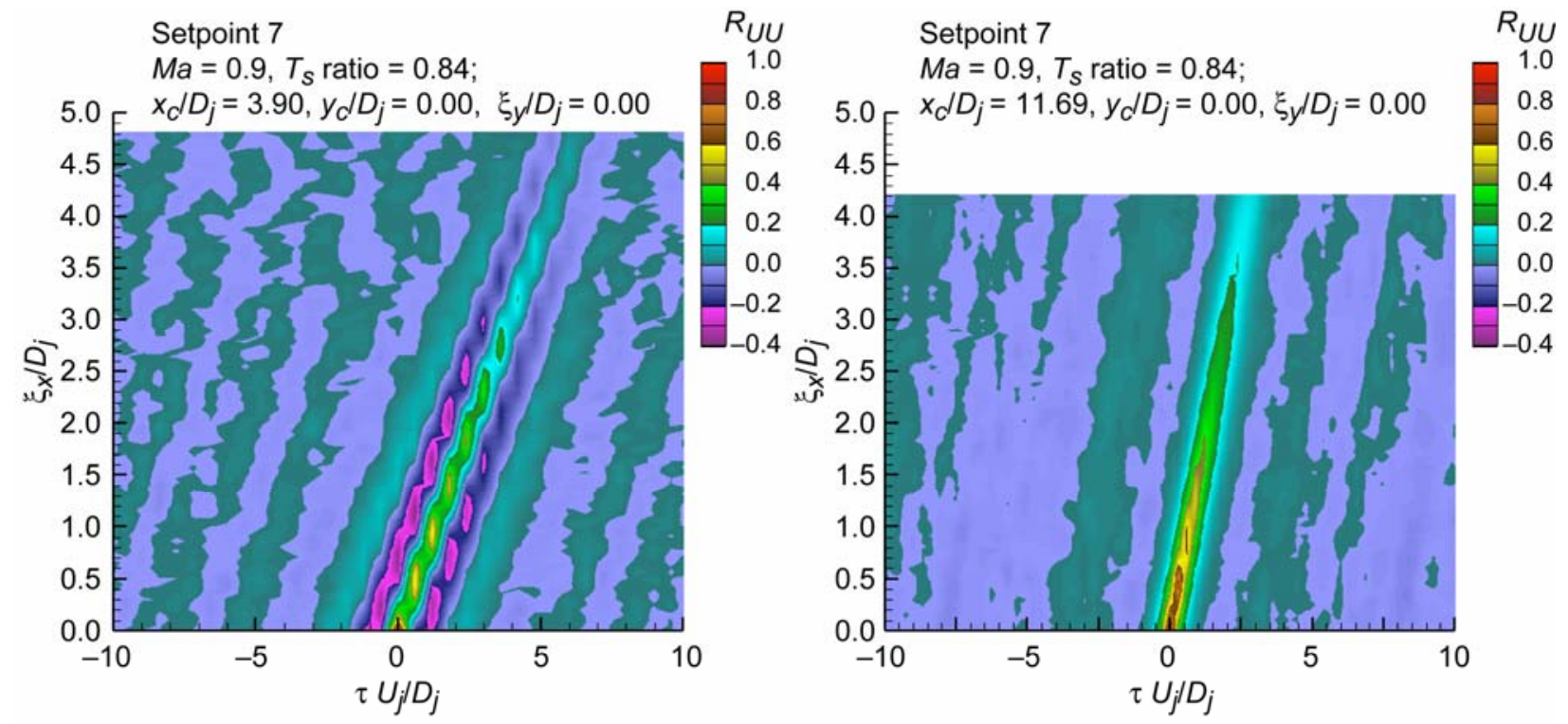

Figure 18.-Space-time correlations of axial velocity, setpoint $7\left(M a=0.9, T_{S} / T_{\infty}=0.84\right)$. Centerpoints of correlations were $x / x_{C}=0.5, y / D=0$ (left), and $x / x_{C}=1.5, y / D=0$ (right). 
For all jet conditions, the correlation changed shape dramatically on the centerline, and on the two sides of the ending of the potential core. Looking across jet conditions at a given reference location, it can be seen that the three conditions with $\mathrm{Ma}=0.9$ but at different temperature ratios (first, third, and fifth columns) were relatively similar. In fact, the main distinctive differences which were noted, was how the correlations within the potential core of the two hot jets at $\mathrm{Ma}=1.33$ were different from the three subsonic cases at $\mathrm{Ma}=0.90$ (top two rows of figure 19). Again, this may not be significant because there is very little turbulent kinetic energy within the potential cores of the jets. These contour plot show that the two-point space-time correlation of turbulent velocity fluctuations in jets are not affected by temperature to a significant level that could possibly compensate for the reduction in jet density due to the heat. The correlations are relatively insensitive to temperature.

\section{Discussion}

Overall, the present study showed that the turbulence spectra for the unheated and heated jets were similar; except for a small increase in overall turbulent kinetic energy due to the heat. If any, the most noticeable difference was observed in the initial stage of the heat addition (fig. 15). Among the hot jets, the velocity spectra were extremely similar, differing in most places by less than the $1 \mathrm{~dB}$ scatter of the measurement.

The biggest question raised by the data presented in this paper is why the velocity spectra changed so abruptly with the addition of heat, and then remained insensitive to the temperature. Were there differences in the turbulence caused by the addition of heat to the flow? Were there systematic bias errors introduced by the heating of the gas?

The jet was heated by combusting hydrogen well upstream of the nozzle, with an air to fuel ratio in the thousands. Heating of the jet added a slight amount of water vapor, calculated to be much less than the change typically seen in daily fluctuations in ambient relative humidity. This seems as an unlikely source of error to influence the hot jet's statistics.

Possible changes in the measurement system with the addition of heat have also been investigated. Both heated and unheated jets were seeded in a similar fashion. Optical distortion is always a concern when working with a hot flow, but if such distortions were present they should have caused a bias that strengthened with temperature, not a one-step change as observe here. The measurements made in previous years with other PIV configurations agreed well with the current measurements even though they used different optical paths in their setup. To date, no reason has been found not to believe the results presented here, although measurements of lower temperature heated jets are planned as well to further investigate this apparent singularity.

\section{Conclusions}

One easy conclusion from this paper is that Time-Resolved Particle Image Velocimetry (TR-PIV) promises to be a great tool for future investigations of turbulence in jets. In principle, the data acquired with such a system will be able to deliver all sorts of velocity statistics required by theoreticians working on source modeling and jet noise prediction. For the data acquired in the current test, in view of the work presented elsewhere that specifically addresses the measurement error, the accuracy of the first order statistics was within a few percent of generally accepted values. Current limitations of the technique to $10 \mathrm{kHz}$, and the inability to properly anti-alias the acquisition, puts some limits on the accuracy of spectral measurements, particularly at the highest frequencies. The quality of these statistics and practical limitations will have to be expanded in future work. The present effort focused mainly on the impact of temperature on turbulent velocity statistics, and was successful in providing answers to some important questions posed in aeroacoustic.

Turbulence measurements were analyzed to understand the impact of temperature on noise sources. The first impact was the previously observed changes in potential core length, captured by the correlation of Witze. The second impact noted was that the unheated $\mathrm{Ma}=0.90$ jet had a turbulence field nearly 
10 percent less than that of the next lowest static temperature ratio $\left(T_{s} / T_{\infty}=1.76\right)$. However, the turbulence level did not change with additional increase in temperature up to $T_{s} / T_{\infty}=2.27$. Aside from this, jet temperature did not change the spectral characteristics or the space-time correlations of the turbulence once changes in the potential core length were reflected into the axial positions at each measurement point. Significant differences in spectral shapes and space-time correlations were noted on the two sides straddling the ending of the potential core. It was also noted that these differences may not be important because of the relatively low level of turbulent kinetic energy within the potential core.

\section{References}

1. Laurence, J.R., "Intensity, scale, and spectra of turbulence in mixing region of free subsonic jet," NACA Report 1292 (1956).

2. Bridges, J., "Measurements of turbulent flow field in separate flow nozzles with enhanced mixing devices-test report," NASA/TM-2002-211366, (2002).

3. Bridges, J. and Wernet, M.P. "Measurements of the aeroacoustic sound source in hot jets," AIAA Paper 2003-3130 (2003).

4. Brown, C.A., and Bridges, J., "Small Hot Jet Acoustic Rig Validation," NASA/TM-2006-214234 (2006).

5. Tam, C.K.W., and Ganesan, A., "A Modified k- $-\varepsilon$ Turbulence Model for Calculating the Mean Flow and Noise of Hot Jets," AIAA Journal, vol. 42, no. 1, 2004, pp. 26-34.

6. Doty, M.J., and McLaughlin, D.K., "Two-Point Correlations of Density Gradient Fluctuations in High Speed Jets Using Optical Deflectometry,” AIAA Paper 2002-0367, Jan. 2002.

7. Tam, C.K.W., Pastouchenko, N.N., And Viswanathan, K., "Fine-scale turbulence noise from hot jets," AIAA Journal, vol. 43 (8), 2005, pp. 1675-1683.

8. Khavaran, A., and Kenzakowsky, D. "Noise prediction in hot jets," AIAA Paper 2007-3640 (2007).

9. Bridges, J., "Effect of heat on space-time correlations in jets," AIAA Paper 2006-2534 (2006).

10. Witze, P.O., "Centerline velocity decay of compressible free jets," AIAA Journal vol. 12(4), 417-418 (1974).

11. Brown, C.A., and Bridges, J., "Acoustic efficiency of azimuthal modes in jet noise using chevron nozzles," AIAA Paper 2006-2645 (2006).

12. Wernet, M.P., "Time Resolved PIV for Space-Time Correlations in Hot Jets," 2007 AIAA Aerospace Sciences AIAA paper (2007).

13. Wernet, M.P. "Temporally resolved PIV for space-time correlations in both cold and hot jet flows" Meas. Sci. Technol. 18 (2007), 1387-1403.

14. Tanna, H.K. et al. "The generation and radiation of supersonic jet noise, part III, Turbulent mixing noise data," AFAPL-TR-76-45, (1976). 


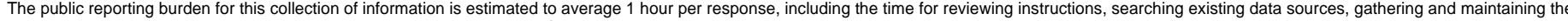
data needed, and completing and reviewing the collection of information. Send comments regarding this burden estimate or any other aspect of this collection of information, including suggestions for reducing this burden, to Department of Defense, Washington Headquarters Services, Directorate for Information Operations and Reports (0704-0188), 1215 Jefferson Davis Highway, Suite 1204, Arlington, VA 22202-4302.

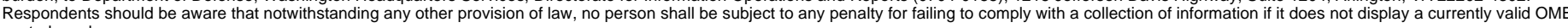

PLEASE DO NOT RETURN YOUR FORM TO THE ABOVE ADDRESS

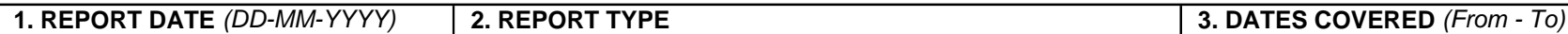

01-10-2007

Technical Memorandum

\section{TITLE AND SUBTITLE}

Effect of Temperature on Jet Velocity Spectra

5a. CONTRACT NUMBER

5b. GRANT NUMBER

5c. PROGRAM ELEMENT NUMBER

\section{AUTHOR(S)}

Bridges, James, E.; Wernet, Mark, P.

\section{5d. PROJECT NUMBER}

5e. TASK NUMBER

5f. WORK UNIT NUMBER

WBS 984754.02.07.03.04.02

\section{PERFORMING ORGANIZATION NAME(S) AND ADDRESS(ES)}

National Aeronautics and Space Administration

8. PERFORMING ORGANIZATION

John H. Glenn Research Center at Lewis Field

REPORT NUMBER

Cleveland, Ohio 44135-3191

E-16149

\section{SPONSORING/MONITORING AGENCY NAME(S) AND ADDRESS(ES)}

National Aeronautics and Space Administration

Washington, DC 20546-0001

\section{SPONSORING/MONITORS ACRONYM(S) NASA}

\section{SPONSORING/MONITORING REPORT NUMBER \\ NASA/TM-2007-214993; AIAA-2007- 3628}

\section{DISTRIBUTIONIAVAILABILITY STATEMENT}

Unclassified-Unlimited

Subject Categories: 7 and 34

Available electronically at http://gltrs.grc.nasa.gov

This publication is available from the NASA Center for AeroSpace Information, 301-621-0390

\section{SUPPLEMENTARY NOTES}

\section{ABSTRACT}

Statistical jet noise prediction codes that accurately predict spectral directivity for both cold and hot jets are highly sought both in industry and academia. Their formulation, whether based upon manipulations of the Navier-Stokes equations or upon heuristic arguments, require substantial experimental observation of jet turbulence statistics. Unfortunately, the statistics of most interest involve the space-time correlation of flow quantities, especially velocity. Until the last 10 years, all turbulence statistics were made with single-point probes, such as hotwires or laser Doppler anemometry. Particle image velocimetry (PIV) brought many new insights with its ability to measure velocity fields over large regions of jets simultaneously; however, it could not measure velocity at rates higher than a few fields per second, making it unsuitable for obtaining temporal spectra and correlations. The development of time-resolved PIV, herein called TR-PIV, has removed this limitation, enabling measurement of velocity fields at high resolution in both space and time. In this paper, ground-breaking results from the application of TR-PIV to single-flow hot jets are used to explore the impact of heat on turbulent statistics of interest to jet noise models. First, a brief summary of validation studies is reported, undertaken to show that the new technique produces the same trusted results as hotwire at cold, low-speed jets. Second, velocity spectra from cold and hot jets are compared to see the effect of heat on the spectra. It is seen that heated jets possess 10 percent more turbulence intensity compared to the unheated jets with the same velocity. The spectral shapes, when normalized using Strouhal scaling, are insensitive to temperature if the stream-wise location is normalized relative to the potential core length. Similarly, second order velocity correlations, of interest in modeling of jet noise sources, are also insensitive to temperature as well. 15. SUBJECT TERMS

Jet flow; Turbulence; Correlation; Jet aircraft noise; Particle image velocimetry; Velocity distribution; Prediction analysis techniques; Navier-Stokes equation; Laser anemometers; Velocity measurement; High resolution; Temperature effects

\begin{tabular}{|c|c|c|c|c|c|}
\hline 16. SECURI & ASSIFICATION & & 17. LIMITATION OF & 18. NUMBER & 19a. NAME OF RESPONSIBLE PERSON \\
\hline $\begin{array}{l}\text { a. REPORT } \\
U\end{array}$ & $\begin{array}{l}\text { b. ABSTRACT } \\
\text { U }\end{array}$ & $\begin{array}{l}\text { c. THIS } \\
\text { PAGE } \\
\text { U }\end{array}$ & UU & $\begin{array}{c}\text { PAGES } \\
23\end{array}$ & $\begin{array}{l}\text { 19b. TELEPHONE NUMBER (include area code) } \\
301-621-0390\end{array}$ \\
\hline
\end{tabular}



